\title{
Further Studies of Asynaptic Maize
}

By

\section{G. W. Beadle*}

William G. Kerckhoff Laboratories of the Biological Sciences, California Institute of Technology, Pasadena, California

(With Plates 6 and 7)

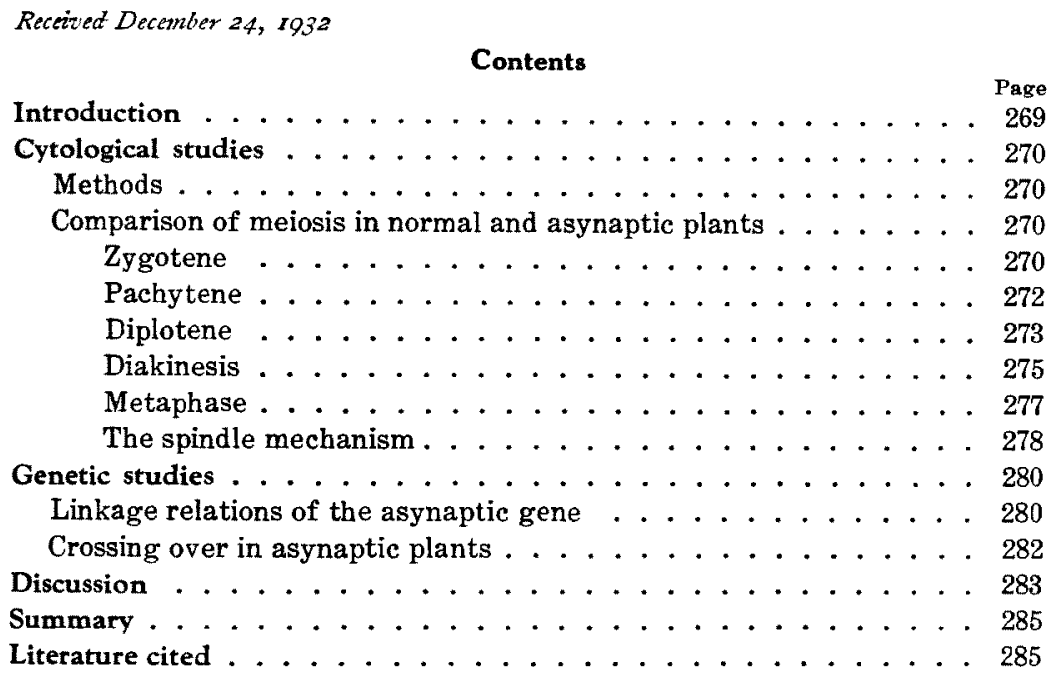

\section{Introduction}

The asynaptic gene was reported by Beadle and McClintock (1928) and Beadle $(1930)^{1)}$. It was shown that the asynaptic character is inherited as a simple Mendelian recessive. Cytologically, asynaptic plants are characterized by a general lack of first meiotic metaphase pairing of chromosomes. The studies of meiotic prophase chromosomes

* National Research Council Fellow in the Biological Sciences.

1) In view of the observations recorded in the present paper it is clear that the name "asynaptic" is inappropriate for the character under consideration. It is retained to avoid confusion in terminology. 
were limited in extent and, in other respects, were unsatisfactory. The present paper includes (1) a redescription of meiosis in asynaptic plants with particular reference to the prophase conditions, (2) data on the linkage relations or the asynaptic gene and (3) some data on the effect of the asynaptic gene on crossing over.

\section{Cytological studies \\ Methods}

Cytological studies of meiosis were confined to microsporogenesis. The aceto-carmine method was used exclusively. The procedure is summarized briefly as follows :

1. Anthers were fixed in acetic acid and alcohol (30:70 parts) for 24 to 48 hours.

2. Sprocytes were teased out in a small quantity of aceto-carmine and Ehrlich's haematoxylin (4:1 parts).

3. A larger amount of weak aceto-carmine was added and a cover glass applied.

4. The slides were heated gently to flatten cells and clear the cytoplasm (McClintock, 1929).

5. The mounts were sealed with a paraffin and gum mastics mixture.

The above outlined method gives rapid staining, good contrast and fair keeping qualities of the preparations.

\section{Comparison of meiosis in normal and asynaptic plants}

Unfortunately no complete account of meiosis in maize is available. Pachytene, diakinesis, metaphase and later stages have been studied rather extensively (Randolph, 1928; McClintock, 1929, 1930 and 1931). The stages at which synapsis takes place and the stages between pachytene and diakinesis have been given less attention. Some studies of normal plants are reported in the present paper; they serve as a basis of comparison with asynaptic plants. In all cases the normal plants studied were sibs of asynaptic plants which were studied cytologically.

Zygotene

By the use of methods employed in the studies reported here, the chromatin is drawn into a tight knot (synizesis) at the stages at which 
synapsis takes place. It is difficult to study material in such stages. In the case of asynaptic plants, one of the points to be determined is whether or not synapsis takes place. This question can be answered without directly studying the process. If homologous chromosomes can be seen to be intimately paired at later stages, we know that synapsis must have taken place. Synizetic stages were studied in asynaptic plants which showed little associations of homologous chromosomes at metaphase (see Text fig. 2). In preparations of such stages, occasional segments of chromosomes can be found which are more or less separated from the knot of chromatin. Many such segments were studied carefully. They were found, in all cases, to be double (Pl. 7, Figs. 19 and 20) and presumably represented synapsed homologs. That this doubleness does not represent the equational split in unpaired chromosomes is indicated by the fact that as successively later stages are observed the proportion of apparently single threads increases (Pl. 7, Figs. 21 and 22). Furthermore, identifiable regions of specific chromosomes were paired at early stages. This point was established by studying the satellite chromosome. A particular region of this chromosome is found associated with the nucleolus (McClintock, 1931). In asynaptic plants, this and adjacent regions of the satellite chromosome were, in many figures, found to be paired at early stages ('Text fig. 1). As a matter of fact, regions of the satellite chromosomes near
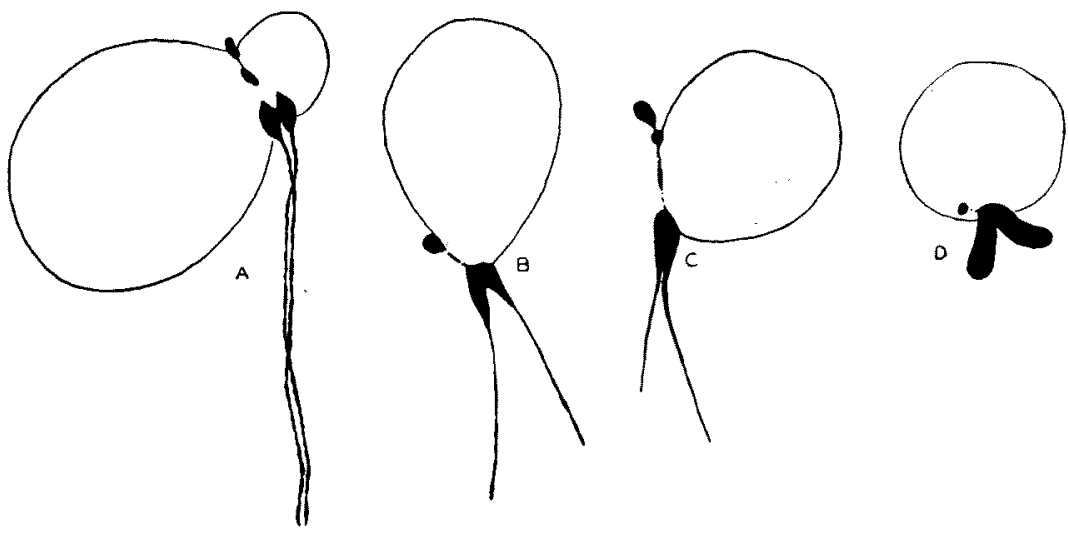

Text fig. 1. The behavior of the satellite chromosome in asynaptic plants. A, Synizesis showing synaptic pairing. $B$ and $C$, Early diplotene showing association at point of attachment to nucleolus and failure of association at adjacent regions. D, Diakinesis showing association at point of attachment to nucleolus. A, B and C represent incomplete chromosomes. $(\times 1565)$. 
the point of attachment to the nucleolus remain associated thoughout pachytene and diakinesis, i.e., until the disappearance of the nucleolus (Text fig. 1). The association of these regions is presumably the result of their attachment to the nucleolus in close proximity. Segments of the homologous satellite chromosomes not close to the region of attachment of the nucleolus, in most cases, were separate at later stages (PI. 7, Fig. 23; Text fig. 1). In these unpaired threads the equational split usually was not evident.

Recently McClintock (1932) has found that maize plants heterozygous for various chromosomal rearrangements, deficiencies and duplications frequently show apparent synapsis of non-homologous segments. Such apparent synapsis does not lead to association at diakinesis and metaphase and therefore presumably not to chiasma formation and crossing over.

The demonstration of the occurence of this apparent synapsis of non-homologous parts suggested that asynaptic gene in maize might produce its effect by, in some way, rendering the synaptic attraction forces non-specific, i.e., allowing for a high frequency of synapsis of non-homologous parts. This possibility seems improbable on two grounds: (1) According to McClintock, the apparent synapsis of nonhomologous sections is persistent through pachytene. Paired threads in asynaptic plants fall apart in late synizesis or early pachytene. (2) Identifiable regions of the satellite chromosomes apparently synapse regularly as pointed out above.

Pachytene

Pachytene stages in normal maize have been studied extensively by McClintock (1931). Homologous chromosomes are paired closely at this stage (Pl.6, Fig. 1). The association is, according to McClintock, an intimate chromomere-by-chromomere pairing. Occasionally, however, non-homologous segments apparently are synapsed (McClintock, 1932).

In asynaptic plants the amount of pairing at pachytene ${ }^{\mathbf{1}}$ is variable in different plants. Pachytene stages were studied in eight different

1) In a consideration of meiosis in an abnormal form such as asynaptic maize, the use of a terminology based on the normal meiotic process may be confusing. Pachytene, for example, is used in asynaptic plants for stages at which the chromosomes are unpaired but at which they would normally be paired throughout their lengths as indicated by their degree of contraction. Such a comparison of stages in abnormal with those in normal forms obviously presents difficulties but nevertheless it seems to the writer to be the simplest way of describing the observations. 
plants showing a wide range in amount of association at metaphase (see Text fig. 2). The amount of pairing in pachytene was found to be correlated roughly with the amount of pairing at metaphase. Apparently the falling apart of synapsed homologs in asynaptic plants occurs during pachytene. Since pachytene stages extend over a considerable period of time, a close correlation between degree of pairing at pachytene and metaphase association could not be expected. If the interpretation of chromosome behavior in asynaptic plants presented above is correct, then the amount of pairing at pachytene would be diminishing with time. Since the various substages of pachytene are difficult to identify, any correlation which might exist would be very difficult, if not impossible, to measure.

\section{Diplotene}

Little is known about diplotene stages in maize despite the important bearing of studies of such stages on questions of chiasma frequency, crossing over and chromosome association at later stages. Some studies of diplotene stages in normal maize are presented in the present paper. They were made primarily to serve as a control for studies of asynaptic plants. They are, in no sense, considered to be adequate. The technic used is, in many respects, unsatisfactory and the observations are not extensive.

The pachytene pairs open out in early diplotene at various regions along their length (Pl. 6, Figs. 2 and 3). The important question of how this opening out occurs, whether always in the reductional plane or in both reductional and equational planes, is, thus far, not satisfactorily answered. Later, definite loops and nodes are observed (Pl. 6, Figs. 4 to 14). The structure of the nodes is difficult to make out. In individual cases they can be identified as chiasmata but in most cases the individual chromatids can not be followed. Presumably most of them represent chiasmata ${ }^{1)}$. The spindle attachment regions, in many cases, appear not to separate. What are assumed to be such

1) The term "chiasma" is used in a rather loose sense in this paper. The term is most conveniently used in a morphological sense to designate a change of partners between pairs of chromatids (Darlington, 1931). By the use of the methods employed in the studies reported here chromatids usually can not be followed and therefore in most cases a node can not be positively identified as a chiasma. Furthermore, terminal associations may not be chiasmata in the above sense but they are probably the result of terminalized chiasmata (Darlington, 1932a; Beadle, 1932). For the sake of convenience the term chiasma is used in this paper to refer to any interstitial or end association between homologous chromosomes. 
regions are often observed as thin drawn out threads (Pl. 6, Figs. 4, 5,13 and 14). This drawing out is possibly due to mechanical stretching during flattening of the cells. Whether or not the spindle attachments of homologous chromosomes always tend to remain together after other regions separate is not knowr. In any case, such a behavior of the spindle attachment regions would serves as a serious source or error in a determination of the number of chiasmata.

In spite of the difficulty just mentioned and others, an attempt was made to determine the frequency of chiasmata during such stages as are illustrated in Pl. 6, Figs. 4 to 14 . Such counts as have been made are presented in Table 1. Errors introduced by a possible lag in the separation of the spindle attachments have not been taken into account. For this reason the values obtained are probably too high. The maximum correction for failure of opening out of spindle attachments is, of course, one chiasma per bivalent. There is an additional source of

Table 1. Chiasma frequency per bivalent in normal ( 2 plants) and in " high-pairing"' asynaptic (plant 3701-1) maize plants.

\begin{tabular}{|c|c|c|c|c|c|}
\hline \multirow{3}{*}{$\begin{array}{l}\text { Number of } \\
\text { chiasmata per } \\
\text { bivalent }\end{array}$} & \multicolumn{5}{|c|}{ Frequency } \\
\hline & \multicolumn{2}{|c|}{ Normal } & \multicolumn{3}{|c|}{ Asynaptic } \\
\hline & Diplotene $*$ & Diakinesis & Diplotene & Diakinesis & Metaphase $\dagger$ \\
\hline 0 & 0 & 0 & 3 & 5 & 50 \\
\hline 1 & 0 & 27 & 3 & 26 & 49 \\
\hline 2 & 6 & 72 & 9 & 9 & 171 \\
\hline 3 & 23 & 1 & 4 & 0 & \\
\hline 4 & 32 & 0 & 1 & & \\
\hline 5 & 14 & & 0 & & \\
\hline 6 & 2 & & & & \\
\hline 7 & 1 & & & & \\
\hline $\begin{array}{l}\text { Total no. } \\
\text { bivalents }\end{array}$ & 78 & 100 & 20 & 40 & 270 \\
\hline $\begin{array}{c}\text { Av. no. chiasmata } \\
\text { per bivalent }\end{array}$ & 3.7 & 1.8 & 1.8 & 1.1 & 1.4 \\
\hline $\begin{array}{l}\% \text { chiasmata } \\
\text { terminal }\end{array}$ & 26 & 82 & 30 & 89 & - \\
\hline
\end{tabular}


error in that counts do not represent complete nuclei, i.e., in a given nucleus it may have been possible to interpret only one or two bivalents satisfactorily. This, of course, allows for a systematic error of selection. Such an error can obviously be completely avoided only by studying preparations in which all chromosomes of all nuclei can be interpreted or in which a specific chromosome pair can be interpreted in all nuclei.

At the stages studied, approximately 26 per cent of the chiasmata (uncorrected) appeared to be terminal. This suggests that at an earlier stage the number of chiasmata might have been greater.

As pointed out in the section on pachytene stages the homologous chromosomes in asynaptic plants tend to separate during such stages. In the event of such a separation there is apparently no chiasma formation. In those pairs of chromosomes which remain together over at least a part of their length, diplotene opening out appears to be normal, that is, with chiasma formation.

Some counts of chiasma frequency during diplotene were made on an asynaptic plant which showed a high frequency of bivalent association at metaphase (plant 3701-1, Text fig. 2). These data (Table 1) indicate a reduced frequency of chiasma formation. General observations on other asynaptic plants show clearly that the low frequency of chiasmata per bivalent in diakinesis is significant. A statistical study of the proportion of paired threads and of the frequency of chiasmata per unit length of paired threads in asynaptic plants, though desirable, has not been attempted.

\section{Diakinesis}

Diakinesis has been extensively studied in maize by Randolph (1928), McClintock (1929) and others. During this stage the chromosomes are much contracted as compared with their condition at earlier stages. Homologous chromosome usually are associated terminally (Pl. 6, Figs. 15 and 16). The nature of these terminal associations is not clearly understood but it is reasonable to suppose that they are related to chiasmata which have undergone terminalization (Darlington, 1931 and 1932; Beadle, 1932). Some determinations of the frequency of chiasmata in bivalents in normal maize were made. They are shown in Table 1.

Most of the bivalent pairs are associated terminally only. Of the total number of chiasmata, 82 per cent were terminal. As shown in Table 1, there was an average of 1.8 chiasmata per bivalent. 
276

G. W. BEADLE

Cytologia 4
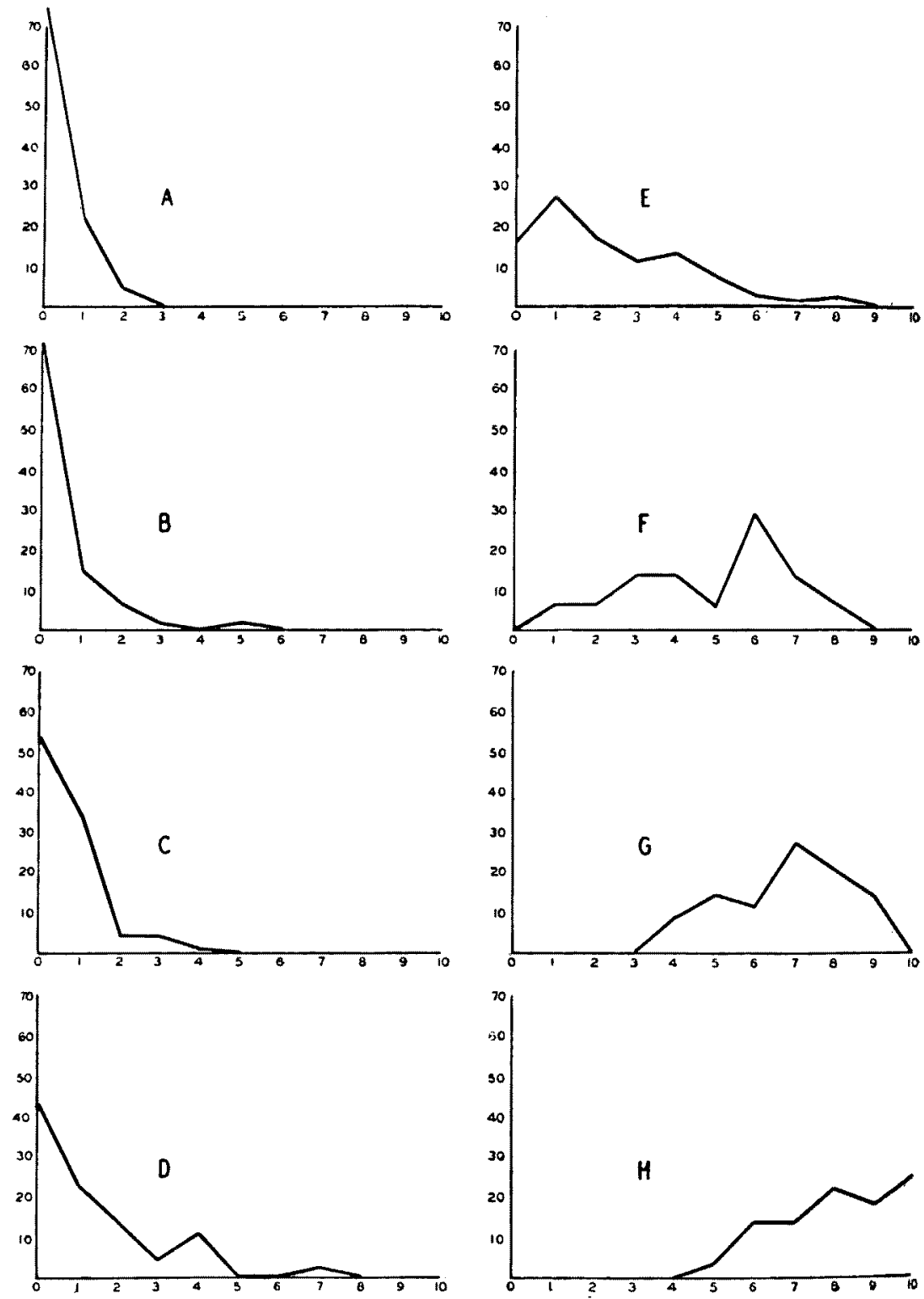

Text fig. 2. Frequency distributions of cells with varying numbers of bivalent at metaphase in eight asynaptic plants. Ordinates represent frequency in per cent of total population and abscissas the number of bivalent. Curves A, B, C, D, E, F, G and $\mathrm{H}$ represent distributions in plants $3695-5,3694-5,3694-14,3693-3,3696-24,3699-14$, 3695-7 and 3701-1 respectively. 
Diakinesis in asynaptic plants resembles the corresponding stage in normal maize with the exception that homologous chromosomes are frequently not associated (Pl. 7, Figs. 24 and 25). Counts of the frequency of chiasmata per bivalent were made on a plant showing a high frequency of bivalent association (the same plant on which diplotene counts were made-Text fig. 2). These counts are presented in Table 1. Here, as at diplotene, the number of chiasmata per bivalent is lower than in the normal control. The observed difference is significant as shown by untabulated observations on many other asynaptic plants.

\section{Metaphase}

The metaphase stage of meiosis in normal maize has been described and figured by several investigators (see Randolph, 1928 and McClintock, 1929 for discussion and references to literature). Metaphase bivalents in maize are characteristically spindle-shaped (Pl.6, Fig. 18). The various shapes assumed by such bivalents can be correlated with the number and position of chiasmata which presumably are responsible for the association of the partners (Darlington, 1932a).

During metaphase in asynaptic plants there are, as in diakinesis, many unassociated chromosomes (Pl. 7, Fig. 26). The number of univalent chromosomes varies in different microsporocytes of the same plant and, to a greater degree, in microsporocytes of different plants. Data on the frequency distribution of cells with different numbers of

Table 2. Distribution of microsporocytes of asynaptic plants with respect to number of bivalents at metaphase $I$.

\begin{tabular}{|c|c|c|c|c|c|c|c|c|c|c|c|c|c|}
\hline \multirow{2}{*}{$\begin{array}{c}\text { Plant } \\
\text { number }\end{array}$} & \multicolumn{9}{|c|}{ Number of bivalents per cell } & \multirow{2}{*}{$\begin{array}{l}\text { Total } \\
\text { cells }\end{array}$} & \multirow{2}{*}{$\begin{array}{l}\text { Av. no. } \\
\text { bivalents } \\
\text { per cell }\end{array}$} & \multicolumn{2}{|c|}{$\begin{array}{l}\text { Minimum no. } \\
\text { chiasmata }\end{array}$} \\
\hline & $\begin{array}{lll}0 & 1 & 2\end{array}$ & $\$$ & & 4 & 5 & 6 & 7 & 8 & 910 & & & $\begin{array}{l}\text { potential } \\
\text { bivalent }\end{array}$ & $\begin{array}{c}\text { Av. per } \\
\text { actual } \\
\text { bivalent }\end{array}$ \\
\hline $3695-5$ & $\begin{array}{lll}17 & 5 & 1\end{array}$ & & & & & & & & & 23 & 0.3 & 0.03 & 1.00 \\
\hline $3694-5$ & $42 \quad 9 \quad 4$ & & 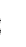 & 0 & 1 & & & & & 58 & 0.5 & 0.06 & 1.14 \\
\hline $3694-14$ & 42274 & & 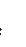 & 1 & & & & & & 78 & 0.6 & 0.09 & 1.35 \\
\hline $3693-1$ & 158 & & 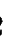 & 4 & 0 & 0 & 1 & & & 35 & 1.3 & 0.17 & 1.28 \\
\hline $3696-24$ & 101610 & & t & 8 & 4 & 2 & 1 & 2 & & 60 & 2.4 & 0.29 & 1.19 \\
\hline $3699-14$ & 11 & & 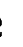 & 2 & 1 & 4 & 2 & 1 & & 14 & 4.9 & 0.68 & 1.40 \\
\hline $3695-7$ & & & & 3 & 5 & 4 & 9 & 7 & 5 & 33 & 6.8 & 1.31 & 1.62 \\
\hline $3701-1$ & & & & & 1 & 4 & 4 & 6 & 57 & 27 & 8.2 & 1.45 & 1.78 \\
\hline
\end{tabular}


univalents for eight asynaptic plants are shown in Table 2. These data are represented diagrammatically in Text fig. 2. There is good reason to suppose, judging from observations on fertility, that more extreme variants occur. The distribution of plants, with respect to fertility, in different cultures suggests that this variability has a genetic basis.

Assuming that the association of each arm homologous chromosomes at metaphase is dependent on chiasmata formed in them (Darlington, 1931), one can, from the shape of a given bivalent, estimate the minimum possible number of chiasmata necessary for the association. This has been done and, although it is admitted that the determinations are difficult to make and are subject to rather serious errors, there appears to be a correlation between number of bivalents per cell and average minimum number of chiasmata. This relation is shown graphically in Text fig. 3, and is readily understandable on the basis of

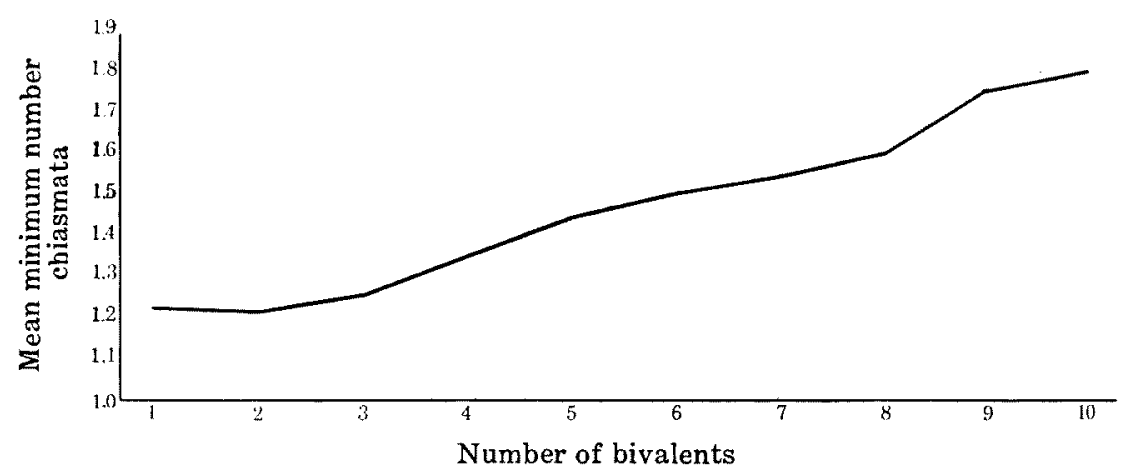

Text fig. 3. Relation between number of bivalents per cell and mean minimum number of chiasmata per bivalent in asynaptic plants.

Darlington's theory of post-diplotene association. Few chiasmata can obviously result in but few bivalents and these will tend to have the minimum number of chiasmata, namely, one. A similar relation was found to exist in Triticum by Hollingshead (1932).

The spindle mechanism

The first meiotic spindle is often much longer in asynaptic than in normal plants (Beadle, 1930). An attempt was made to obtain quantitative data bearing on this point. Measurements were made on cells stained with aceto-carmine and flattened. The spindle, in most cases, was not sharply differentiated and the measurements are therefore only approximate. Furthermore, no account was taken of the normal 
change in spindle length from metaphase to telophase. It should be remembered that metaphase and anaphase stages are not easily distinguished in sporocytes which show no metaphase pairing of chromosomes. Spindles were measured along their median axes which, in the case of asynaptic sporocytes, were usually curved. Lengths are expressed as a ratio of spindle length to greatest diameter of the flattened sporocyte (Table 3). It is clear, in spite of the sources of error involved in the measurements, that the spindles in asynaptic

Table 3. Ratio of length of first meiotic metaphase or anaphase spindle to greatest diameter of cell in flattened sporocytes of normal and asynaptic plants. The observed sporocytes in the asynaptic plant showed no pairing.

\begin{tabular}{c|c|c}
\hline \multirow{2}{*}{ Ratio } & \multicolumn{2}{|c}{ Distribution } \\
\cline { 2 - 3 } & Normal (3696-18) & Asynaptic (3694-5) \\
\hline 0.7 & 4 & 0 \\
0.9 & 17 & 0 \\
1.0 & 19 & 1 \\
1.1 & 4 & 2 \\
1.2 & 3 & 3 \\
1.3 & 0 & 5 \\
1.4 & & 4 \\
1.5 & & 3 \\
1.6 & & 5 \\
1.7 & & 5 \\
1.8 & & 1 \\
1.9 & & 0 \\
\hline Total no & & 1 \\
\hline Mean ratio & & 30 \\
\hline
\end{tabular}

sporocytes are longer than those of normal sporocytes. In fact, the spindle in asynaptic sporocytes which show no metaphase pairing is, on the average, longer than the greatest diameter of the cell. This means, of course, that it must be curved to accomodate itself within the cell (Pl. 7, Fig. 26). The measurements indicate further that the first meiotic spindles in asynaptic plants are more variable in length than those in normal plants.

The abnormal elongation of the spindle in the microsporocytes of asynaptic plants most probably is related to the failure of metaphase 
pairing. The nature of this relation is not entirely clear. Apparently the interacting forces operating on the spindle and chromosomes are in some way altered. It is possible that the paired chromosomes at metaphase resist separation by the spindle mechanism and hence tend to check elongation of the spindle itself. Such a view is inconsistent with the hypothesis that the paired chromosomes undergo initial separation autonomously (Bělař, 1929). It is known that the unpaired chromosomes in asynaptic plants are scattered more or less at random through the spindle. This failure or orientation on the equatorial plate may be the cause of the abnormal elongation of the spindle. This is consistent with the view that the metaphase bivalents mutually repel one another (see Kuwada, 1929 for discussion and references to the literature). Such a mutual repulsion of bivalents lying on the equatorial plate might be expected to prevent undue elongation of the spindle. Unpaired chromosomes distiributed through the spindle should, then, offer less resistence to elongation.

\section{Genetic studies}

\section{Linkage relations of the asynaptic gene}

The asynaptic gene lies in the $P-b r$ chromosome approximately midway between $P$ (pericarp color) and $b r$ (brachytic culm) genes which cross over with a frequency of about 40 per cent.

Since asynaptic plants are highly sterile, it is difficult to obtain backcross progenies in large numbers. However, by making many pollinations sufficient data were obtained to indicate the approximate location of the asynaptic gene.

Counts of the $\mathrm{F}_{2}$ progeny of the cross as $\times P$ gave the following results :

$\begin{array}{ccccc}P+ & P \text { as } & ++ & +a s & \text { Total } \\ 248 & 40 & 30 & 47 & 365\end{array}$

indicating linkage with about 21 per cent of crossing over. Data from the $\mathrm{F}_{2}$ generation of the cross $a s \times b r$ were as follows:

$\begin{array}{ccccc}++ & +b r & a s+ & a s b r & \text { Total } \\ 263 & 86 & 96 & 7 & 452\end{array}$

These data indicate linkage with a crossover value of about 30 per cent. The fine striped gene (f) was segregating in these same cultures but since $b r$ and $f$ are close together (about 5 per cent of crossing over), the complete counts are not tabulated. 
During $1931 \mathrm{~F}_{2}$ progenies of the cross $a s b r \times++$ were grown. The following data were obtained :

$\begin{array}{ccccc}++ & +b r & a s+ & a s b r & \text { Total } \\ 481 & 86 & 108 & 109 & 784\end{array}$

which indicate linkage with a crossover value of about 28 per cent, a value which agrees well with that indicated by the repulsion data.

During 1932, 3- and 4-point backcrosses were grown involving the $P, a s, b r$ and $f$ genes. Data from the cross + as br $f \times \frac{++++}{P \text { as } b r f}$ are shown in Table 4. Total counts involving the three genes as, $b r$ and $f$ are included in Table 5. These data show clearly that the order of the genes concerned is $P$-as-br-f. Additional backcross data involving only the two genes as and $f$ are as follows :

$\begin{array}{ccccc}++ & +f & a s+ & \text { as } f & \text { Total } \\ 92 & 26 & 35 & 67 & 220\end{array}$

Table 4. Data from the 4-point backeross as br $f \times \frac{+a s b r f}{P+++}$

\begin{tabular}{|c|c|c|c|c|c|}
\hline \multirow{2}{*}{$\begin{array}{l}\text { Crossovers } \\
\text { in region- }\end{array}$} & \multirow{2}{*}{ Constitution } & \multirow{2}{*}{$\begin{array}{l}\text { Number of } \\
\text { individuals }\end{array}$} & \multirow{2}{*}{ Total } & \multicolumn{2}{|c|}{ Crossovers } \\
\hline & & & & Total no. & Per cent \\
\hline 0 & $\begin{array}{l}+\quad+\quad+ \\
P \text { as br } f\end{array}$ & $\begin{array}{l}92 \\
62\end{array}$ & 154 & & \\
\hline 1 & $\begin{array}{l}+ \text { as br } f \\
P+++\end{array}$ & $\begin{array}{l}30 \\
32\end{array}$ & 62 & 93 & 30.0 \\
\hline 2 & $\begin{array}{l}++b r f \\
P \text { as }++\end{array}$ & $\begin{array}{l}32 \\
21\end{array}$ & 53 & 78 & 25.2 \\
\hline 3 & $\begin{array}{l}+\quad+\quad+\quad f \\
P \text { as br }\end{array}$ & $\begin{array}{l}3 \\
7\end{array}$ & 10 & 16 & 5.2 \\
\hline 1,2 & $\begin{array}{l}+a s++ \\
P+b r f\end{array}$ & $\begin{array}{l}17 \\
88\end{array}$ & 25 & & \\
\hline 1,3 & $\begin{array}{l}+a s \quad b r+ \\
P++f\end{array}$ & $\begin{array}{l}2 \\
4\end{array}$ & 6 & & \\
\hline Total & & & 310 & & \\
\hline
\end{tabular}


Table 5. Total data from the 3-point backeross as br $f \times \frac{+++}{a s \text { br } f}$ (including dada from Table 4).

\begin{tabular}{|c|c|c|c|c|}
\hline $\begin{array}{l}\text { Crossovers in } \\
\text { region- }\end{array}$ & Constitution & $\begin{array}{l}\text { Number of } \\
\text { individuals }\end{array}$ & Total & $\begin{array}{l}\text { Per cent } \\
\text { crossovers }\end{array}$ \\
\hline 0 & $\begin{array}{lll}+ & + & + \\
a s & b r & f\end{array}$ & $\begin{array}{l}148 \\
115\end{array}$ & 263 & \\
\hline 1 & $\begin{array}{l}+b r f \\
a s++\end{array}$ & $\begin{array}{l}45 \\
48\end{array}$ & 93 & 24.7 \\
\hline 2 & $\begin{array}{l}++f \\
\text { as br }+\end{array}$ & $\begin{array}{r}7 \\
14\end{array}$ & 21 & 5.6 \\
\hline Total & & & 377 & \\
\hline
\end{tabular}

The crossover value here is 27.7 per cent.

From the backeross data discussed above the following crossover valves are obtained:

$$
\begin{array}{lr}
P \text {-as } & 30.0 \% \\
\text { as-br } & 24.7 \% \\
b r-f & 5.6 \%
\end{array}
$$

Although the data involving the three genes $P, a s$ and $b r$ are not extensive, they suggest that there is little or no interference between the $P$-as and $a s-b r$ intervals. More double crossovers were actually obtained than would be expected if there were no interference (observed, 25 ; expected 23.4).

\section{Crossing over in asynaptic plants}

If, as Darlington (1931, 1932) maintains, chiasma formation is a function of crossing over, one might expect a considerable reduction in crossing over in asynaptic plants. The cytological observations clearly indicate a reduction in chiasma frequency. Studies were made of the frequency of crossing over in the $s h-w x$ region of the $C-s h-w x$ chromosome in homozygous asynaptic plants. Crossing over was studied in both mega- and microsporogenesis. The data are presented in Table 6 . There is no indication of a reduction in crossing over when asynaptic plants were used as female parents. The reciprocal crosses suggest a reduction but this is of doubtful significance, considering the normal 
Table 6. Crossing over in the sh-wx region of the $C-w x$ linkage group in asynaptic plants.

\begin{tabular}{|c|c|c|c|c|c|c|c|c|}
\hline \multirow{2}{*}{ Cross } & \multirow{2}{*}{$\begin{array}{l}\text { Number } \\
\text { of } \\
\text { plants }\end{array}$} & \multicolumn{5}{|c|}{ Number of individuals } & \multicolumn{2}{|c|}{ Crossovers } \\
\hline & & ++ & $+w x$ & $\operatorname{sh}+$ & $\operatorname{sh} w x$ & Total & No. & $\%$ \\
\hline$a s \frac{+t}{\operatorname{sh} w x} \times \operatorname{sh} w x$ & 17 & 87 & 23 & 32 & 79 & 221 & 55 & 25 \\
\hline \multirow[t]{2}{*}{$a s \frac{+w x}{s h+} \times \operatorname{sh} w x$} & \multirow[t]{2}{*}{1} & \multirow[t]{2}{*}{5} & \multirow[t]{2}{*}{14} & 8 & \multirow[t]{2}{*}{1} & 28 & 6 & 21 \\
\hline & & & & Total & & 249 & 61 & 24 \\
\hline $\begin{array}{c}+\frac{+\quad+}{\operatorname{sh} w x} \times \operatorname{sh} w x \\
\text { (control) }\end{array}$ & 6 & 469 & 131 & 150 & 447 & 1197 & 281 & 24 \\
\hline $\operatorname{sh} w x \times \frac{++}{\operatorname{sh} w x} a s$ & 1 & 272 & 37 & 29 & 343 & 581 & 66 . & 11 \\
\hline \multirow[t]{2}{*}{.,$\quad \times \quad}$, & 1 & 64 & 17 & 11 & 45 & 137 & 28 & 20 \\
\hline & & & \multicolumn{3}{|c|}{ Total } & 718 & 94 & 13 \\
\hline
\end{tabular}

variability of crossing over in this region (Stadler, 1926; Collins and Kempton, 1927). No comparable control is available for the series in which asynaptic plants were used as pollen parents.

An interpretation and discussion of the available data on crossing over in asynaptic plants is reserved for a later section of this paper (see page 272).

\section{Discussion}

The cytological observations reported in this paper indicate that the characteristics of asynaptic plants are not due to failure of initial synapsis of homologous chromosomes. Rather these characteristics appear to be due to abnormally early separation of synapsed homologs without the formation of chiasmata. The fact that the falling apart of homologs takes place earlier than in normal plants suggests some early disturbance of the meiotic mechanism. One can imagine, assuming Darlington's precocity theory of meiosis, that the equational split in the chromosomes appears early and enables falling apart of pairs of chromatids. Such an interpretation would necessitate the appearance of the effective equational split early enough to reduce the frequency. of or entirely prevent the formation of chiasmata but not early enough 
to prevent the original synapsis. Other assumptions which would account for the failure of metaphase pairing but which do not explain the early separation of homologs and which are in other ways inconsistent with the observations are as follows:

(1) Non-specific synaptic affinities resulting in synapsis of nonhomologous chromosome segments (McClintock, 1932). Such synapsis might be expected to lead to separation without chiasma formation.

(2) Failure of chiasma formation allowing for complete separation of homologous chromosomes.

(3) Complete breakage of chiasmata (Sax's $(1930,1932)$ hypothesis of crossing over).

(4) Lack of "terminal affinity" (Darlington, 1932) allowing for terminalization of chiasmata without resultant association of homologous chromosomes.

Studies of crossing over in asynaptic plants should have a bearing on the above possibilities. If chiasma formation is suppressed or reduced in frequency, crossing over should likewise be reduced. If, on the other hand, chiasmata undergo early and complete breakage, crossing over might be expected to show an increase. From the crossover data (Table 6) it seems unlikely that crossing over is increased. It may be decreased but this is doubtful. It should be pointed out that the crossover data presented in this paper may have little bearing on these questions. The variability in degree of association of homologous chromosomes in asynaptic plants has been considered. In studying crossing over in such plants, the most fertile plants are automatically selected, particularly in the case of those used as pollen parents. Hence, the plants in which crossing over was studied probably represented variations toward the normal. The chances of recovering a normal ten chromosome gamete from a sporocyte with a large number of unpaired chromosomes are obviously poor $\left(\left(\frac{1}{2}\right)^{n}\right.$ where $n$ is the number of unassociated "pairs"). The determinations of minimum number of chiasmata necessary for the observed metaphase configurations (Table 2) indicate that cells with ten bivalents may have approximately the normal number of chiasmata. It is therefore quite certain that the samples of chromosomes studied for crossing over were strongly selected and, in no sense, give a fair measure of the average crossing over in the plants from which they came. This difficulty can be obviated by studying crossing over in the diploid gametes of asynaptic plants. Such gametes probably come from sporocytes with little or no association of chromosomes (Beadle, 
1930). Such studies, obviously, involve testing triploid progeny for genetic constitution and have not, as yet, been carried out.

The cytological observations on meiosis in asynaptic plants support Darlington's hypothesis that post-diplotene association of homologous chromosomes is occasioned by chiasmata". The argument is clear. Synapsis takes place. Chiasma formation is reduced in frequency. Reduced frequency of association at diakinesis and metaphase is expected. The expectation is realized.

\section{Summary}

Synapsis occurs, apparently normally, in asynaptic maize plants.

Homologous chromosomes tend to separate during pachytene without chiasma formation.

Chiasma frequency is low at diplotene, diakinesis and metaphase.

The degree of metaphase pairing in asynaptic plants is variable. The plants studied showed the maximum possible range in modal frequency of number of bivalents, namely, from 0 to 10 .

There is a positive correlation between number of bivalents at metaphase and minimum number of chiasmata which must be assumed to account for the observed associations.

The observations support Darlington's hypothesis of post-diplotene association of homologous chromosomes by chiasmata.

In asynaptic sporocytes which show no metaphase pairing of chromosomes the spindle is considerably longer than in comparable normal sporocytes. This elongation of the spindle in asynaptic plants is probably related either to the lack of metaphase pairing or to the lack of orientation of chromosomes on the equatorial plate.

Crossing over in asynaptic plants, as measured in the normal ten chromosome gametes, is approximately normal, presumably because such gametes make up a highly selected sample.

The asynaptic gene is located in the $P-b r$ chromosome approximately midway between the $P$ and $b r$ genes.

\section{Literature cited}

Beadle, G. W., Genetical and cytological studies of Mendelian asynapsis in Zea mays. 1930 Cornell Agr. Exp. Sta. Memoir 129: 1-23.

1) This hypothesis is, of course, independent of any hypothesis concerning the mechanism of crossing over. 
Beadle, G. W., The relation of crossing over to chromosome association in Zea1932 Euchlaena hybrids. Genetics 17: 481-501.

- and McClintock, B., A genic disturbance of meiosis in Zea mays. Science $192868: 433$.

Bělař, K., Beiträge zur Kausalanalyse der Mitose. II. Untersuchungen an den Sper1929 matocyten von Chorthippus (Stenobothrus) lineatus Panz. Arch. f. Entwm. $118: 359-484$.

Collins, G. N. and Kempton, J. H., Variability in the linkage of two seed characters 1927 in maize. U.S. Dept. Agr. Bull. 1468: 1-64.

Darlington, C. D., Meiosis. Biol. Revs. $6: 221-264$.

1931

1932 Recent advances in cytology. Churcbill, London.

Hollingshead, L., The occurrence of unpaired chromosomes in hybrids between 1932 varieties of Triticum vulgare. Cytologia 3: 119-141.

Kuwada, Y., Chromosome arrangement I. Model experiments with floating magnets 1929 and some theoretical considerations on the problem: Mem. Coll. Sci., Kyoto Imp. Univ. $B, 4: 199-264$.

McClintock, B., A method for making aceto-carmin smears permanent. Stain 1929 a Tech. 4: 53-56.

1929b A cytological and genetical study of triploid maize. Genetics 14: 180-222.

1930 A cytological demonstration of the location of an interchange between two 1930 non-homologous chromosomes of Zea mays. Proc. Nat. Acad. Sci. 16:791796.

1931 Cytological observations of deficiencies involving known genes, trans-

1931 locations and an inversion in Zea mays. Res. Bull. Mo. Agr. Exp. Sta. 163: 1-30.

Cytological observations in $Z e a$ on the intimate association of non-homolo-

1932 gous parts of chromosomes in the mid-prophase of meiosis and its relation to diakinesis configurations. Proc. Sixth Int. Congress Genet. 2: 126-128.

Randolph, L. F., Chromosome numbers in Zea mays L. Cornell Agr. Exp. Sta. 1928 Memoir 117: 1-44.

Sax, K., Chromosome structure and the mechanism of crossing over. Journ. Arnold 1930 Arb. 11: 193-220.

1932 The cytological mechanism of crossing over. Ibid. 13:179-212.

Stadler, L. J., The variability of crossing over in maize. Genetics 11:1-37.

1926

\section{Explanations of plates \\ Plate 6}

First meiotic division in normal maize

(Figs. 1 to 11, $\times 1520$; Figs. 12 to $18, \times 620$. Assumed spindle attachments indicated by arrows).

Fig. 1, Pachytene.

Figs. 2, 3, Beginning of diplotene opening out.

Figs. 4-14, Diplotene showing chiasmata.

Figs. 15, 16, Diakinesis.

Fig. 17, Late diakinesis.

Fig. 18, Metaphase. 


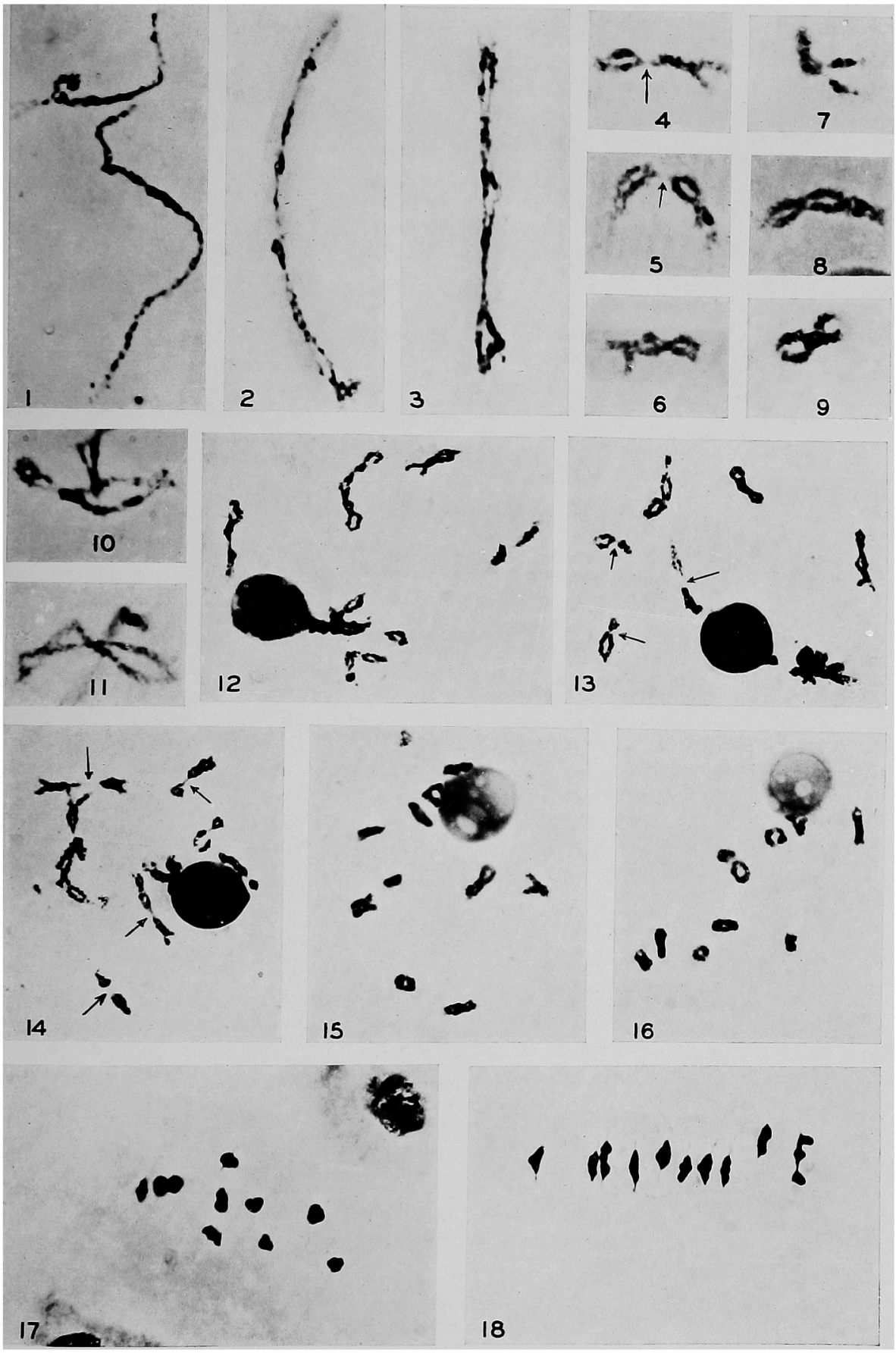

Beadle: Further studies of asynaptic maize 


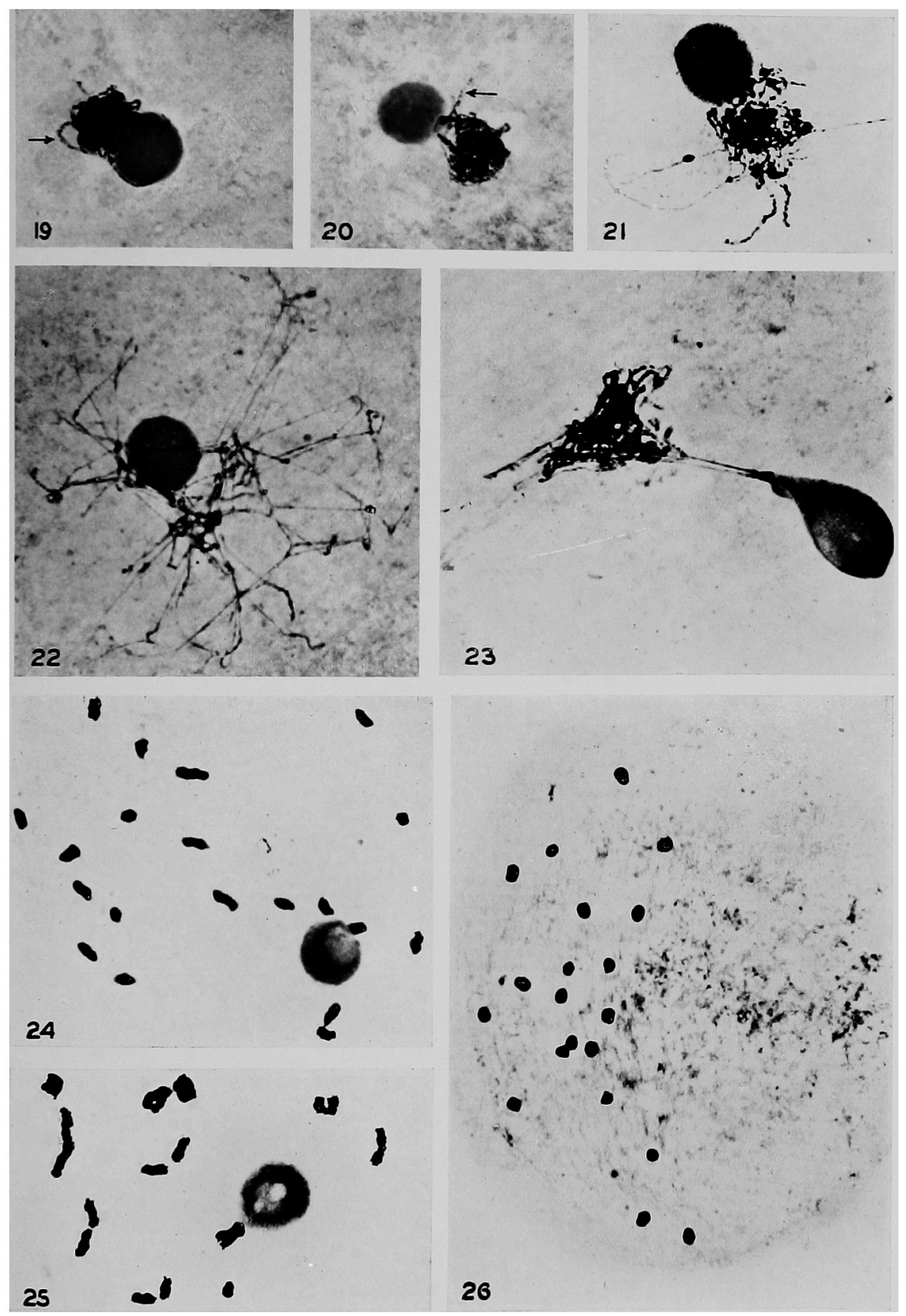

Beadle: Further studies of asynaptic maize 
Plate 7

First meiotic division in asynaptic maize $(\times 620)$

Figs. 19, 20, Synizesis showing double threads (arrows).

Fig. 21, Late synizesis showing both double and single threads.

Fig. 22, Pachytene showing mostly single threads.

Fig. 23, Synizesis showing that homologous parts of the satellite chromosomes

(attached to nucleolus) had paired.

Fig. 24, Diakinesis showing 20 univalents.

Fig. 25, Diakinesis showing five rod bivalents and one univalent (B-type chromo-

Fig. 26, Metaphase-anaphase showing 20 univalents lying in a curved spindle.

\section{Note added to proof:}

Since the present manuscript was sent to the press Dr. C. D. Darlington (paper in press) has studied the frequency and movement of chiasmata in normal maize. His results differ from those reported in this paper in three ways, namely, in showing (1) a lower average frequency of chiasmata at diplotene, (2) a higher average frequency at diakinesis and (3) less terminalization. Two factors may have contributed to the first difference, (1) earlier stages were studied in the present paper and (2) the lag in separation of spindle attachments (see text). The second difference seems to me to be a real one. My results show a much higher proportion of bivalents at diakinesis with a single chiasma than do Darlington's. It is difficult to account for this on the basis of differences in interpretation. The genetic constitutions of my stocks as well as the conditions under which they were grown differed from those studied by Darlington. It is possible that such differences might account for the difference in results. As regards the third difference, I do not believe the discrepancy is as great as the data would indicate. The methods used by both Darlington and myself swell the chromosomes considerably and the determination of whether chiasmata near the ends are actually terminal or not is more or less arbitrary. I am convinced that there was real difference in interpretation in this respect. 